Andrea Carolina Martínez Arcos*, Gissell Natalia Gómez Saavedra**

\title{
De la semiótica visual a la semiótica de la moda: identificando el color durante la Ruta Libertadora ${ }^{1}$
}

\author{
Independence Campaigns Clothing: Color analysis and its \\ semiotics meaning
}

Cómo citar:

Gómez, G. \& Martínez, A. (2019). De la semiótica visual a la semiótica de la moda: identificando el color durante la Ruta Libertadora. Designia, 7(1), 85-115.

\author{
${ }^{1}$ Este análisis hace parte de la investigación en curso "Reconocer \\ nuestro patrimonio - Indumentaria durante la Ruta Libertadora" del \\ grupo de investigación Patrimonio y Memoria \\ de la Universidad de Boyacá (PAME). \\ *Diseñadora Industrial de la Universidad de los Andes, Magister \\ en Ingeniería Textil, Papelera y Gráfica de la Universidad \\ Politécnica de Cataluña (Barcelona, España). \\ Experta digital en diseño textil e indumentaria en la Universidad \\ Tecnológica Nacional de Buenos Aires (Argentina). Docente de \\ Diseño de Modas en la Universidad de Boyacá. \\ E-mail: acmartineza@uniboyaca.edu.co \\ ORCID: https://orcid.org/0000-0001-7456-2047 \\ **Diseñadora de Moda de la Universidad de Boyacá, Especialista \\ en Gerencia de Mercadeo. Candidata a Magister en Diseño para \\ Industrias Creativas y Culturales en la Universidad El Bosque \\ (Bogotá). Docente de Diseño de Modas en la Universidad de Boyacá. \\ E-mail: gisgomez@uniboyaca.edu.co \\ ORCID: https://orcid.org/0000-0003-1973-2298
}

Palabras clave:

Color, semiótica visual,

indumentaria, Ruta Libertadora.

Key words:

Color, visual semiotics, clothing,

Ruta Libertadora.

Recibido: 27/08/2019

Aceptado: 02/04/2020

\section{Resumen:}

El presente artículo trata sobre el análisis del color del vestuario como posible rasgo diferenciador a nivel territorial y de época, lo que sirve como principal herramienta para identificar grupos culturales y sociales representados en la indumentaria colombiana en el periodo de 1810 a 1820. Este análisis hace parte de la investigación en curso "Reconocer nuestro 
patrimonio - Indumentaria durante la Ruta Libertadora", la cual tiene por objetivo documentar e identificar los elementos del diseño de moda tales como estructura, forma, color y demás rasgos visuales y técnicos que permitan establecer un discurso propio con respecto al traje, el diseño textil y su tendencia propia de la época y la región.

Como proceso metodológico se llevó a cabo una recopilación de información visual, obtenida a través de fuentes cartográficas e ilustraciones de indumentaria que fuesen pertinentes y correspondieran con los principales protagonistas de la gesta libertadora. Para ello se realizó una clasificación de imágenes, entre las que se incluyen personajes del ejército patriota, así como realistas, mestizos y criollos.

Este estudio sistemático permite reconstruir con datos todo aquello relacionado con el vestuario de la época en Boyacá. En específico, y en lo que se refiere a este artículo, se toma como caso de estudio el color como recurso fundamental de la semiótica visual, para así comprender el código cromático y su relación con los seis ejes fundamentales planteados por Bernd Löbach (1981), para las funciones de los productos y su relación con el hombre y el objeto: lo estético, lo funcional, lo social, lo sensorial, lo formal y los efectos. Este enfoque logra evidenciar la influencia del vestuario francés, inglés y español en aquel momento de la historia, y cómo construye las preferencias de los grupos sociales en sus actividades.

Con los resultados obtenidos de esta investigación se busca establecer una serie de pautas para un futuro proyecto que permita entender el fenómeno cromático en el universo de la indumentaria ligada al costumbrismo de la época, para así aportar a la memoria de la historia de la región y del diseño. 


\section{Abstract:}

This article treats the analysis of clothing color as a possible distinguishing feature at the territorial level and about a specific point in the history of Colombia, which serves as the main tool to identify cultural and social groups represented in Colombian clothing in the period from 1810 to 1820. This analysis makes part of the ongoing investigation "Recognizing our heritage Clothing during the Ruta Libertadora"; which aims to document and identify the elements of fashion design such as structure, shape, color and other visual and technical features that allow us to establish our own discourse regarding clothing, textile design and its own trend of time and region.

As a methodological process, a compilation of visual information obtained through cartographic sources and clothing illustrations was carried out, which were pertinent and corresponded to the main protagonists of the liberating feat. For this, the classification of images is carried out, which includes characters from the patriot and realist armies, as well as mestizo and creole people.

This systematic study allows us to reconstruct with data everything related to the wardrobe of that period in Boyacá. Specifically, and with regard to this article, color is taken in a case study as a fundamental resource of visual semiotics, in order to understand the color code and its relationship with the 6 fundamental axes proposed by Bernd Löbach (1981), about the functions of products and their relationship with man and object: aesthetic, functional, social, sensorial, formal and effects. This approach manages to show the influence of the French, English, and Spanish costumes at that moment in history, and how it builds the preferences of social groups and their activities.

With the results obtained from this research, the aim is to establish a series of guidelines for a future project that allows us to understand the chromatic phenomenon in the universe of clothing linked to the customs of the time, in order to contribute to the memory of the history of the region and the design. 


\section{INTRODUCCIÓN}

La semiótica se podría definir como un mecanismo de análisis e interpretación que se ocupa de la manera como se construyen los mensajes y como se comunican a los demás, además de analizar los lenguajes y la cultura que se refleja en sus contenidos (Verón, 1993). Los mensajes son una mezcla de subjetividades, pues dependen del observador y de la manera como identifica una imagen, y de cómo genera sentido gracias a la interacción de la forma, el mensaje y sus efectos. Para esta interpretación se asume la semiología que propone Saussure (2014), como una ciencia que estudia la existencia de los signos en el seno de la vida social, cuyos elementos se exponen a continuación.

Hablando desde las funciones del lenguaje, la forma refiere a la manera como se expresan los signos bajo la influencia del contexto y cómo pueden llegar los mensajes de una manera clara en el universo personal. En el caso del vestuario, es la persona mediante su indumentaria quien emite mensajes para expresar las maneras en las que quiere ser vista o cómo quiere tener contacto con el otro. En cuanto al mensaje, para que este funcione requiere de un referente y una interpretación, por ello este debe construirse bajo una serie de heterogeneidades culturales, cargadas de elementos simbólicos, que identifican específicamente una prenda de vestir hasta universalizarla (por ejemplo, en el concepto de un pantalón). Los efectos son inesperados, es difícil construir una hipótesis sobre los resultados que se causen sobre otro por el hecho de vestir cierta tipología de vestimenta, pues ello depende del contexto y del receptor.

Esta disciplina "es un claro ejemplo del tipo discursivo, puesto que se refuerza la relación entre un 'yo' y un 'tú', es decir, un uno que asume representarse a través de la moda y un otro al que se dirige; este vínculo genera un impacto o dialogo polifónico con alto intercambio de contenidos" (Radulescu, 2017), una experiencia del ser humano y de su manera de proyectarse hacia los demás, generando un patrón de conducta. 
Por otra parte, cuando se habla específicamente sobre la semiótica en la indumentaria como un producto cultural, existen diversos elementos y estructuras en el traje que intervienen entre el emisor y el receptor a niveles estéticos, funcionales, sociales, de los sentidos, de formas y de efectos; estos son: el código de color (tonos cromáticos), las formas y las estructuras (cortes o siluetas), y las simbologías (derivadas en el diseño textil). La importancia de todos estos elementos radica en saber traducir la narrativa de la moda a través de cortes, superposiciones, colores y formas que permiten dar estructura y movimiento al cuerpo; Radulescu (2017) dice que es a través de la corporalidad y la anatomía que existe una dinámica e interacción con el vestuario, la cual crea tensiones tales como: asimilación-exclusión, lo vivido y lo construido, identidad y cambio, sentido y diferencia, formas de alteridad y elecciones estratégicas, presencia ante sí y ante el mundo. En conclusión, dichos elementos nos permiten entender qué significado hay detrás de todo ello y su forma de representarse en un contexto influenciado por la cultura, donde la moda será abordada por su usuario desde el concepto de identidad como un ser/estar y querer/poder/hacer.

Se debe entender entonces que toda prenda de vestir está cargada de significados, gracias a las relaciones existentes con el espacio y sus definiciones culturales, entendiendo al ser humano como un protagonista que tiene un espacio en la sociedad, y que propone diversas dinámicas de subjetividad y heterogeneidad, como componentes constitutivos y referenciales de la historia de un lugar.

\section{La semiótica visual}

Según Polidoro (2016), la semiótica es una disciplina metodológica que tiene dos perfiles o manifestaciones: la explicativa (la parte teórica que describe cómo funciona el lenguaje o los sistemas de signos) y la práctica o analítica (la parte descriptiva en la cual articula una serie de instrumentos metodológicos dirigidos a descubrir el sentido de los textos). Teniendo en cuenta lo anterior, es importante aclarar que no solo lo que se encuentra escrito es susceptible de ser interpretado y analizado; esto también es claramente posible en el caso del diseño y sus diferentes corrientes (gráfico, industrial, de interiores y de moda), en las que un objeto relacionado con un observador y un emisor se encuentra cargado de signos y significados no hablados, los cuales son construidos culturalmente cuando el observador interviene con ellos. Es por ello que el objeto de la semiótica abarca el estudio de las imágenes, objetos, gestos y demás manifestaciones en las cuales existe una mezcla de lenguajes, con una serie de códigos que se pueden encontrar en todos los sistemas de expresión. 
Para adentrarnos en estos códigos y tipos de elementos comunicacionales la semiótica visual proporciona los instrumentos necesarios que permiten analizar las imágenes y responder a diversas preguntas, tales como las planteadas por Zumalde (2016): ¿Qué convenciones nos permiten reconocer a personajes y situaciones descritos en un cuadro? ¿Qué hacen las imágenes para contar historias? ¿Pueden líneas, espacios y colores tener un significado independiente de aquello a lo que representan? Para ello, la semiótica recurre a la ayuda de otras disciplinas tales como la iconografía y la psicología de la percepción, para la resolución de los códigos usados en este tipo de análisis visual que se presentan a continuación.

\section{Los códigos del análisis visual}

Además de ser la guía para todos esos aspectos perceptivos, psicológicos, gráficos e icónicos que conlleva el análisis de una imagen o de un conjunto de ellas, los códigos se consideran como el eje articulador en la producción de la significación-sentido del mensaje visual. Dentro de los mismos, según Eco (1968), podemos encontrar los siguientes:

a. Códigos perceptivos: La lectura de la imagen implica identificar ciertos códigos de reconocimiento, como sucede con los signos icónicos. Por ejemplo, un hombre que tiene gafas oscuras, cabello blanco largo y viste siempre de negro remite al nombre de Karl Lagerfeld.

b. Códigos de reconocimiento: Estructuran bloques de unidades de reconocimiento; por ejemplo, rayas negras sobre fondo blanco referencian a una cebra.

c. Códigos de transmisión: Son las estructuras que condicionan una transmisión determinada, produciendo una sensación, tales como los pixeles de una imagen, las pinceladas de un cuadro, el reticulado en una foto de prensa y el ligamento en un textil.

d. Códigos tonales: Connotan entonaciones particulares del signo, tales como fuerza, tensión, etc., y otros sistemas ya convencionales, como lo gracioso, lo expresivo, etc.

e. Códigos icónicos: Se definen como un conjunto de reglas no convencionales que establecen la equivalencia entre un signo gráfico determinado y una unidad pertinente del código de reconocimiento. Por ejemplo, la articulación de la forma a través de la unión de líneas y colores. 
f. Códigos iconográficos: Son iconos culturalizados, codifican algunas condiciones de reconocimiento y establecen, por ejemplo, que una mujer semidesnuda al lado de un árbol y una manzana es "Eva en el paraíso siendo tentada".

g. Códigos del gusto y la sensibilidad: Establecen las connotaciones provocadas por los signos icónicos. Por ejemplo, los objetos que guardan connotaciones a lo largo de la historia, como un templo griego, al cual se le atribuyen significados de belleza, perfección, antigüedad.

h. Códigos retóricos: Convencionalización de soluciones icónicas originales, que se convierten en modelos o normas. Aquí lo retórico quiere decir lo efectivo para transmitir un mensaje y producir un efecto dentro de un contexto de emisión.

i. Códigos estilísticos: Codifican soluciones originales o modificadas por la retórica. Son signos que se articulan siguiendo las leyes de un código subyacente (como el código estilístico, que se basa en el código retórico, o el código iconográfico, que se basa en el código icónico).

Ahora bien, cuando se habla de la semiótica visual, podemos establecer que esta se separa en tres áreas, dependiendo del recurso visual utilizado:

- La semiótica de la imagen estática (imágenes icónicas, indiciales, simbólicas, estéticas).

- La semiótica de la imagen dinámica (lenguaje de sordomudos, mímica, teatro, televisión, etc.).

- Una semiótica visual que se puede relacionar con el espacio, la arquitectura, la escultura y la moda. Esta última es mejor conocida como semiótica del vestuario, gracias a los estudios realizados por parte del filósofo italiano Ugo Volli (2001). 
Según Karam (2011), se entiende por semiótica de la imagen el estudio del signo icónico y los procesos de sentido y significación a partir de la imagen. El estudio de la imagen y las comunicaciones visuales en realidad se basa estrictamente en lo pictórico o visual, y como tal puede abordar los análisis de colores, formas, iconos y composición, para dar paso a los elementos históricos y socio-antropológicos que forman parte de la semiótica de la imagen. Puesto que es la imagen una componente fundamental de la cultura, de la vida social y política, estudiar la misma deviene en reflexionar cómo se construye socialmente el sentido en ciertos procesos de comunicación visual; de allí deriva que el estudio de la semiótica visual está circunscrito por el de una semiótica de la cultura, en la medida en que no se reduce únicamente al análisis de los códigos visuales, sino que se refiere a la manera como una imagen forma parte de la representación social, media la relación y construye visiones del mundo.

\section{El significado semiótico del traje}

Luego de identificar que en la semiótica visual son la imagen y el espacio los elementos principales para analizar la dinámica del vestuario, se concluye que el medio significa la manera como el hombre se comunica con los demás, sin necesidad de que intermedie un conjunto de palabras o signos escritos para que sea interpretado.

Esto constituye una cadena de información donde se interpretan sentimientos, la relación con los demás, el contexto y la cultura que de ellos provienen; será la gestualidad la base de la comunicación no verbal del cuerpo a través de un elemento artefactual como lo es la traje, pues el hombre, como señala Medina Caro (2008), intercambia mensajes con los otros a través de los objetos, de la exhibición de elementos materiales en su cuerpo, siendo este un soporte de signos y de símbolos, no solo bajo parámetros funcionales y prácticos, sino además estéticos, que tienen fuerte repercusión en los sentidos humanos. Dichos signos son leídos e interpretados por un agente externo, por un individuo, una comunidad o un grupo social, vinculándolos a nivel cultural con el contexto. 
Es este conjunto de símbolos funcionales y prácticos lo que hace posible la identificación de un traje de cualquier época, puesto que son la clave de las identidades particulares de una sociedad, en la medida en que el vestir está ligado a la corporalidad, lo que facilita a los hombres que se reconozcan unos a otros. El mismo Medina afirma que el vestido, la forma como se lleva, las poses y la gestualidad, los colores, estructuras y formas permiten identificar quién es su portador y a qué grupo pertenece, cuál es su rol en la sociedad y qué lo diferencia de los demás, cuál es el poder que posee y cuáles son sus pretensiones. Es por ello que puede concebirse la moda como un instrumento estético a nivel sociológico que da clara cuenta de las características de una época, de los factores importantes del cambio social, de los estilos de vida dominantes y particulares en un determinado momento histórico, todo lo cual nos ayuda a comprender un proceso cultural interesante más allá de las razones económicas que lo enmarcan.

En El lenguaje de la moda, Lurie (1994) señala que "desde hace miles de años el primer lenguaje que han utilizado los seres humanos para comunicarse ha sido el de la indumentaria", aportando un código que se relaciona con la identidad y cultura social, el cual es definido de la siguiente manera por Davis (1992):

- El primer rasgo de este código reside en que depende del contexto; en función del portador de la indumentaria, el lugar o la ocasión, el significado será diferente.

- La segunda característica del código está en su alto grado de variabilidad social, es decir, el código no significa lo mismo para todos los miembros de la sociedad en el mismo periodo de tiempo.

- Y por último, está lo que él denomina undercoding, siguiendo a Eco (1968). De forma resumida se puede decir que esta situación ocurre cuando, en ausencia de reglas de interpretación fiables, las personas suponen o deducen, a menudo inconscientemente, significados en un texto u otra comunicación. 
De lo anterior, si hacemos un análisis paralelo entre la semiótica y la moda, encontramos que para Zimmerman (1988) el diseño es intrínseco, al igual que el mensaje que este desea comunicar; un estudio o rastreo etimológico de la palabra diseño puede ayudar a construir el argumento que lo relaciona con la dimensión estética, comunicativa y simbólica, traducido como designio o signo con un propósito o intención:

- En latín, diseño y designio tienen en común la raíz seña = signa = signum $=$ señar $=$ señalar $=$ señalizar.

- En francés, dessin= dibujo; dessein= designio.

- En italiano, disegnare, del latín designare $=$ marcar $=$ dibujar $=$ designar $=$ elegir $=$ singularizar $=$ signo de lo singularizado . Designación $=$ asignación $=$ elección de signos $=$ identidad.

- En alemán, Gestaltung = diseño = configuración; Gestalt = forma; $A$ bsicht $=$ designio $=$ Sicht $=$ visión $=$ tener-en-vista-un propósito.

- En griego, di-seño $=$ di $=$ dia $=$ dividido $=$ dos veces $=$ "dos veces el objeto a través del signo" = signo como re-presentación, "evocación de la ausencia de un objeto o referente"; de-signio = "pertenecer a"; di y de = expresa "lo perteneciente a la seña" = lo que posee signo.

Paralelamente, un análisis etimológico de las palabras moda, vestuario, traje e indumentaria muestra lo siguiente:

Moda:

- Latín: modus ("manera"), y entre sus sinónimos: uso, costumbre, novedad

- Francés: mode, modo, modismo, modelo

Vestuario:

- Latín: vestire $($ "ropa" $)$ = investir $=$ revestir $=$ vestido = vestimenta $=$ vestuario, y entre sus sinónimos: uso, costumbre, novedad. Sufijo 'ario' = conjunto o colección.

Traje:

- Latín: trahere ("traer, atraer, contraer, extraer, distraer") = vestido = uniforme = manera de vestir . 


\section{Indumentaria:}

- Latín: indumentum ("vestimenta, conjunto de lo que se lleva puesto"), del verbo induere $=$ vestir, poner.

- Griego: endyma = vestir, meterse en, entrar en.

En línea con lo anterior, para Zimmerman (1988) diseñar es llevar el objeto a su signo, por ello aparece una íntima relación en el traje y su función de otorgar significación, o la finalidad de volverlo costumbre para que adquiera un significado.

\section{Función y estética del vestuario}

Según Volli (2001), cuando no se habla de moda sino del vestuario, es importante evidenciar los efectos que este produce a los sentidos y a la configuración habitual que se les da a los objetos a nivel semiótico, pues la ropa en sí ya tiene un significado cuando se le asigna una función, como es el caso de un uniforme, y en su uso para una ocasión específica, el efecto que esta produzca depende de la armonía del vestuario y sus complementos, así como de quien lleve puesto dicho vestuario; el mismo Volli cita el famoso proverbio "el hábito no hace al monje", dado que este, el hábito, solo lo significa y lo comunica.

Así mismo, en la teoría del lenguaje para los productos de Gros (1984) y Fischer \& Mikosch (1984), la función práctica y la función estética son entre otras cosas mecanismos y/o elementos de comunicación de tipo socioeconómico, es decir, pueden indicar o representar la situación o estatus social de quien viste la prenda, así como el gusto que se maneja sobre un tipo de indumentaria para representar a una persona en un contexto público o para llamar la atención sobre sí misma. Para ello, la moda debe buscar en una prenda un balance entre lo funcional y la idea de lo bello al interior de un grupo humano, a fin de que cumpla con las convenciones de apariencia de un sujeto y de lo que este quiera o deba representar.

Dentro de esas funciones estéticas del objeto se encuentran aquellos aspectos que pueden observarse independientemente del sentido de su contenido, que para el caso del diseño de moda se manifiestan en la importancia de tres elementos básicos y composicionales en una prenda, tales como son la estructura, la forma y el color. 


\section{Estructura, forma y color en la indumentaria}

\section{La estructura}

La moda es un lenguaje visual determinante para la sociedad, un movimiento que aporta distinción entre las personas, establece rangos sociales y se convierte en una expresión cultural indispensable para la humanidad. En ese sentido, el presente análisis describe códigos importantes en las diferentes estructuras y formas implementadas en la época de la independencia que se convirtieron en iconos representativos para los diversos personajes partícipes de tan magno hecho.

Por su parte, la estructura es definida por la Real Academia Española como "la distribución y orden con que está compuesta una obra de ingenio" (RAE, s.f), de tal manera que en la perspectiva de la creación/construcción de la indumentaria se tiene en cuenta el orden con el cual se construye el plano, se cortan las piezas y se ensamblan generando una composición única, con una expresión en específico.

La estructura de un traje es diseñada desde el patronaje, donde cada línea y corte es analizado, proyectado y ubicado de manera estratégica para dar la forma adecuada a la prenda a elaborar sobre el cuerpo. Un ejemplo de lo anterior se encuentra en el vestuario militar, el cual sugiere la idea de alguien imponente, elegante y respetable, como corresponde a aquellos líderes que llevaron dichos atuendos, construidos a partir de una estructura rígida y erguida que demuestra la importancia de mantener su poder y respeto ante la comunidad.

Ricardo Rivadeneira Velásquez (2010), historiador de la Universidad Nacional de Colombia, realizó una síntesis sobre prendas características de la época independentista en la cual resalta la influencia constante de países europeos y los diversos movimientos que se presentaron, rescatando especialmente el neoclasicismo como tendencia de vestuario liderada por Napoleón Bonaparte y su esposa Josefina de Beauharnais. 
Napoleón se caracterizó por sus atuendos con detalles impecables, limpieza y porte apropiado en cada una de sus batallas; fue icono de la moda, líder distinguido y respetable que se convirtió en un personaje representativo para Francia y transmitió toda su ideología a nivel mundial. Así mismo Josefina, mujer de clase alta, distinguida por el lujo y la sobriedad, sirvió como referente de estilo para otras mujeres, impuso el corte imperio en Europa, característico para esa época, y desde allí esta influencia se trasladó a la Nueva Granada y fue adoptada por personajes tales como Manuelita Sáenz, quien adquirió dichos códigos de vestuario dándole un toque nacional.

\section{La forma}

Es importante aclarar que hay ciertos códigos estructurales y formales que se relacionan específicamente con los propuestos por Eco (1968), tales como los códigos tonales, icónicos, de gusto y estilísticos, en la indumentaria. Con todo, la forma está influenciada por un fenómeno de cambio acelerado de signos que la van transformando o modificando de acuerdo a las culturas y a la evolución del mismo material textil.

A pesar de lo anterior preexisten estructuras básicas e intrínsecas desde la confección de la prenda, lo que se conoce como patronaje básico, las cuales constituyen los cimientos para el diseño de una prenda y resultan siendo un elemento visual para distinguir un pantalón de una falda, o un frac de un esmoquin. En ese sentido la forma, los cortes y la silueta que presentan las prendas posibilitan la existencia de rangos distintivos que permiten diferenciarlas por géneros, por edad, por condiciones sociales y por oficio. 


\section{El color}

Dentro de las variables simbólicas en el vestuario se encuentra también el color, el cual posee características tales como la iluminación, el brillo o intensidad, el tono y la temperatura, entre otros. Estas afectan no solo las emociones, sino también, como lo expone Shin (2015), producen oscilaciones cerebrales que se manifiestan en el comportamiento del individuo e influyen en la aceptación de los objetos, o en el caso de la moda, la aceptación del sujeto en la sociedad.

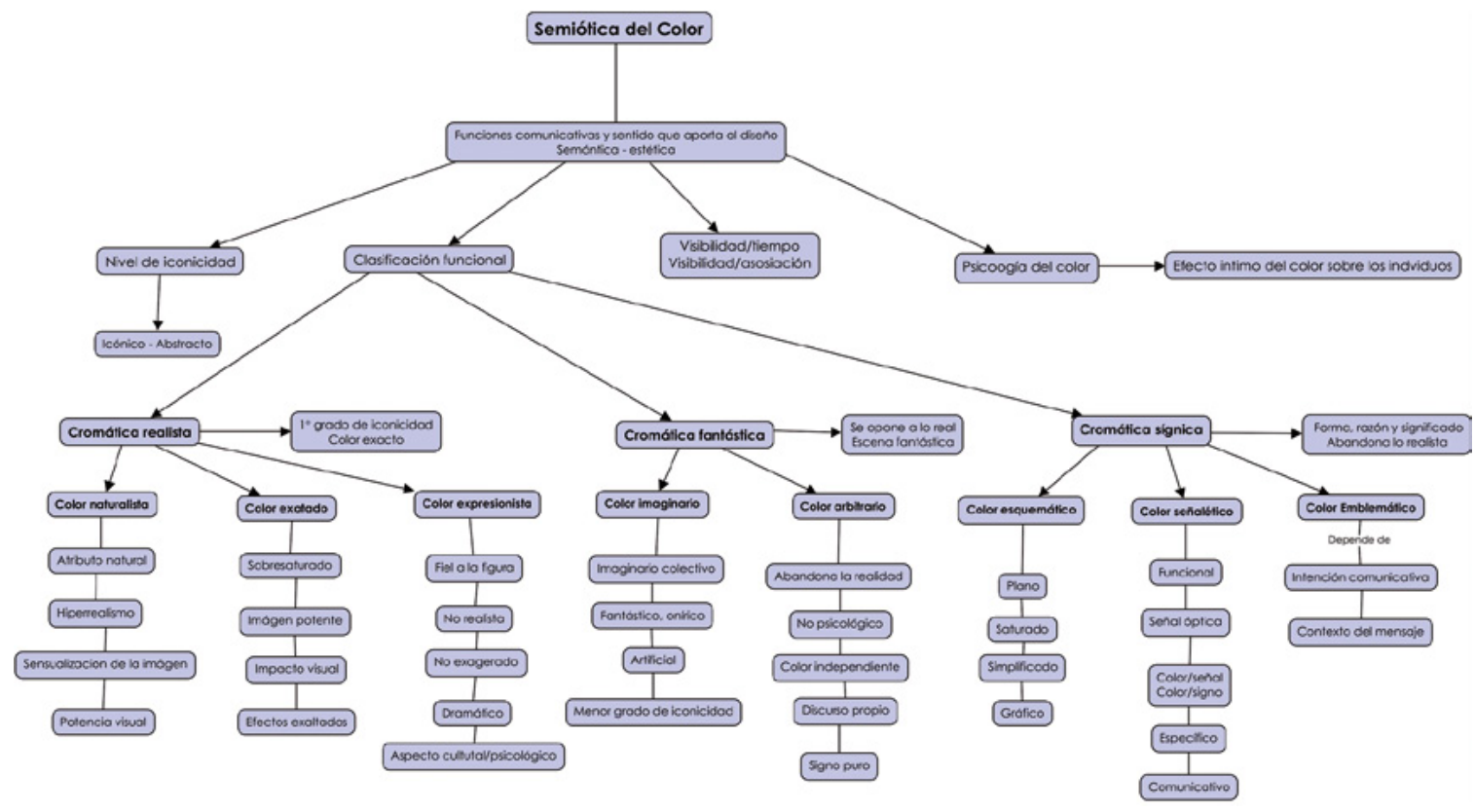

Figura 1: La semiótica del color. Fuente: Costa (2010).

${ }^{2}$ Código: Sistema de designios y reglas que permiten formular y comprender un mensaje. Conjunto de elementos que se combinan siguiendo ciertas reglas para dar a conocer algo. Los códigos se pueden clasificar en gráficos, numéricos, mixtos y lingüísticos.
Estas influencias cromáticas generan códigos ${ }^{2}$ comportamentales y preferenciales en los observadores, interfiriendo así de manera directa en sus emociones y por lo tanto en la forma de responder o tener una postura frente a un contexto y cultura específica; este proceso perceptual se crea de forma particular, y también es estimulado por el entorno que lo rodea. Tal carácter de particularidad nos induce a ver y leer colores diferentes de aquellos que físicamente tenemos delante, y a los cuales les asignamos un significado, ligado específicamente con la psicología del color, la cual establece el lenguaje que expresa cada color. 
Este lenguaje cromático se expresa a nivel funcional y en el vestuario de moda, en la medida en que el uso de los colores depende del oficio que realice una persona. En el contexto histórico que se aborda en este artículo, sirve como elemento diferenciador de clases sociales y bandos militares; el ejército patriota constituye un claro ejemplo, pues en el mismo se evidenciaban las diferentes clases sociales que lo componían, lo que determinó igualmente la forma como fueron percibidos por la sociedad, al punto de que fueron conocidos como el ejército de los harapos. En cuanto a los altos mandos, como Bolívar o Santander, en su uniforme primaba el uso de tonos rojos y oscuros debido a su función en campo de batalla, esto es, el de camuflar o encubrir posibles rastros de sangre. Esta divergencia cromática influyó en el mensaje que transmitía el vestuario del ejército a los observadores externos, al punto de generar una extrema confianza en el bando realista en cuanto a una victoria segura en la contienda.

\section{El código de color en la moda}

De acuerdo con lo anteriormente señalado, el código de color en la moda comprende diferentes variables que permiten darle un significado y analizarlo en el contexto del periodo de la Ruta Libertadora. Estas variables se explican en el siguiente esquema:

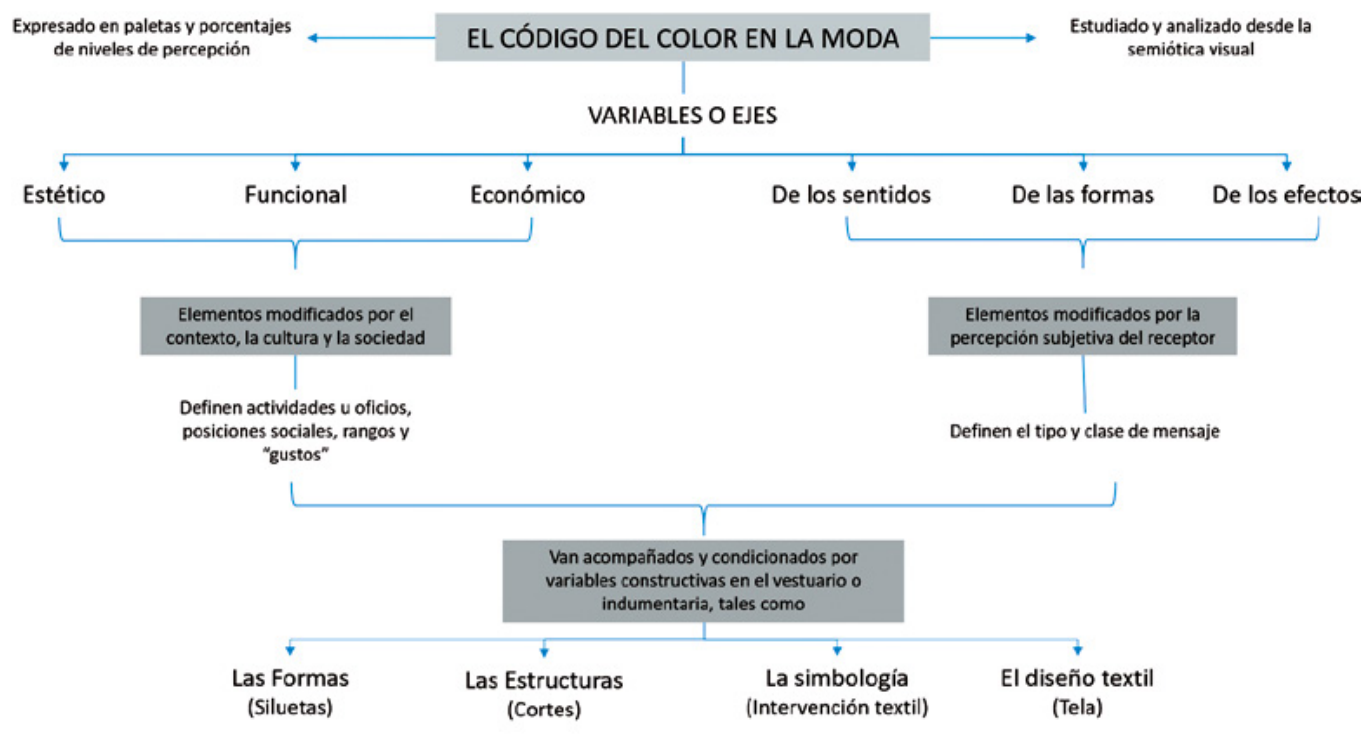

Figura 2. El código del color en la moda. 
Susan Geringer (2001) señala que el color y la forma de una prenda se relacionan para dar un significado objetivo, definiendo de manera puntual cómo cada color perteneciente al círculo cromático básico (primarios, secundarios y terciarios) da valor a la combinación de tonos; según la proporción de la misma en cada prenda de vestir, este aporte permite desarrollar la descripción de cada personaje, como se mostrará a continuación.

La metodología de análisis que se presenta aquí es exploratoria, y toma como base la jerarquía percibida del color a primera vista, medida en una escala básica de $10 \%$ a $100 \%$, que permite dar un orden de tonalidad a cada atuendo con el fin de lograr identificar el contexto social, económico y político del momento. No obstante, es válido aclarar que las imágenes base de este análisis son pinturas de imaginarios.

En el proceso de seleccionar y clasificar las armonías de color es de vital importancia lograr un balance visual, tanto en prendas superiores como inferiores; desde allí, la aplicación equilibrada en un atuendo determinará el impacto que este pueda generar en el contexto. Para identificar el color en el atuendo de estos personajes históricos se implementó una técnica expuesta por Anna María López (2014), especialista en diseño con medios digitales, moda y tendencias, la cual define la relevancia que tiene cada combinación de color en las prendas de vestir, grafías u objetos, y explica cómo utilizarla correctamente según tres aspectos o enfoques mínimos, los cuales se citaran a continuación:

- Color dominante: Es el color principal empleado para llamar la atención del observador, el color predominante de toda la composición gráfica.

- Color subordinado: El color subordinado en un diseño es el color visualmente más débil que complementa al color dominante o contrasta con él.

- Color de énfasis: El color de énfasis, también denominado color de acento, es el empleado para aportar atención a un detalle visual. (López, 2014, pág. 96) 
A partir de lo anterior, se definieron dos herramientas funcionales para ser aplicadas a las imágenes de personajes icónicos de la Ruta Libertadora de Colombia, las cuales fueron la escala porcentual y la categorización propuesta por Anna López, permitiendo una argumentación robusta sobra la definición del uso de color en cada uno de ellos. En la investigación se eligieron tres hombres y tres mujeres que representan diferentes rangos sociales, brindando una información útil para el proceso de observación y posteriormente la creación de paletas cromáticas significativas, obteniendo de este modo una perspectiva de su protagonismo y relevancia en la historia.

La moda se estudia desde un aspecto sociológico que comprende el entorno de cada persona, en tanto la psicología del color profundiza y permite deducir ciertas características y cualidades de la persona. El comprender e identificar los significados del color da pie a entender cómo es el comportamiento humano frente a la selección de atuendos y cómo estos se transforman a su vez en códigos de vestuario para diversos estilos de vida; el color refleja no solo cualidades, sino emociones y sentimientos, atrae o pasa desapercibido ante la sociedad. La argumentación de esta investigación se realizó basándose en narraciones e ilustraciones creadas a partir de testimonios hallados en libros o contados por diversas personas; desde este enfoque, es válido afirmar que la historia es subjetiva y depende de la perspectiva de cada observador. 


\section{Estructura del atuendo y análisis de color}

\section{Vestuario masculino}

En el siguiente análisis se pretendió identificar por medio del código del vestuario los rangos sociales a los cuales pertenecía cada personaje y cuán significativa fue cada prenda al expresar su personalidad, actividades e importancia para ser distinguido en su momento particular. Cada argumento fue construido a partir de narraciones e ilustraciones que permitieran observar el contexto de cada uno.

\section{a. Simón Bolívar}

\section{Simón Bolivar}

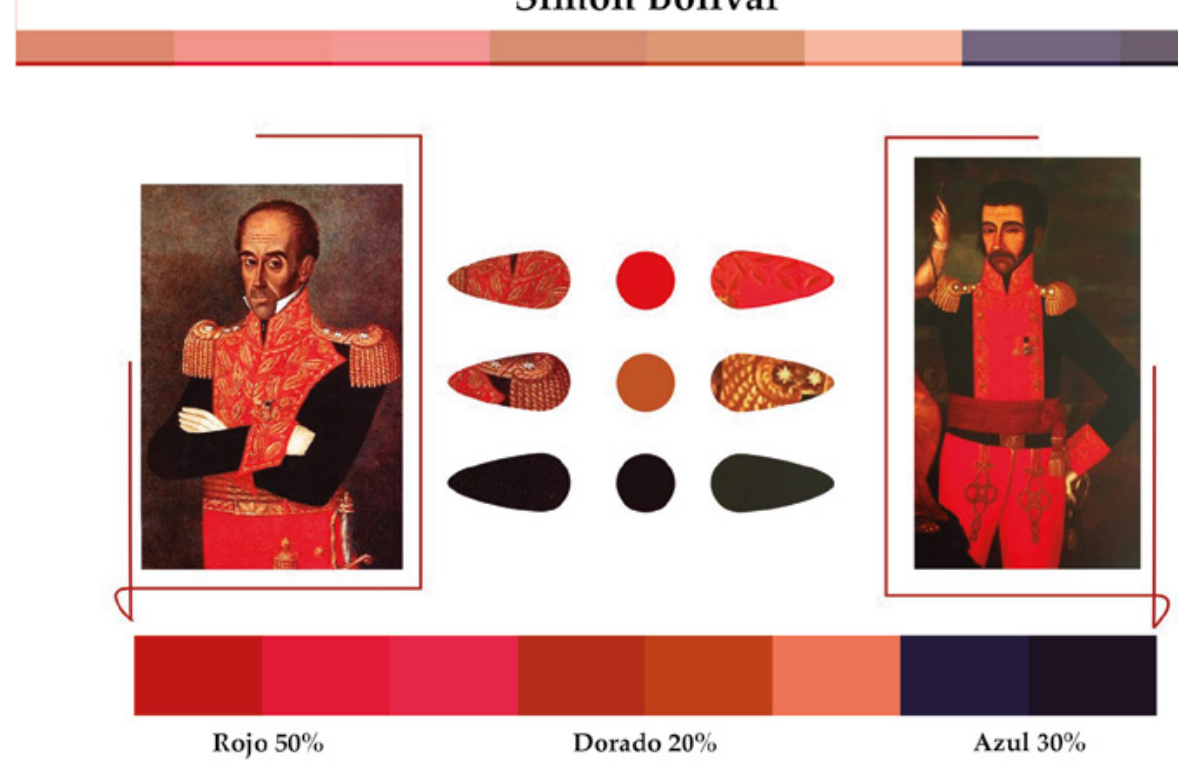

Figura 3. Simón Bolívar (pintura de José María Espinosa, 1830). Recuperado de: https://www.pressreader.com/colombia la-opinion-imagenes/20171029/281530816278629

Figura 4. Bolívar con la América India (detalle; pintura de Pedro José Figueroa, 1819). Recuperado de: https://www.ifch.unicamp.br/eha/chaa/conf_yobenj.php 
En diversas ilustraciones de Simón Bolívar y otros personajes históricos se distingue una gama de colores tradicionales neutros, inspirados en atuendos militares españoles, ingleses y sobretodo franceses. El Libertador, un hombre de carácter fuerte, líder y defensor, siempre vestía una paleta de color clásica, donde el azul y el rojo escarlata eran la base de su elegancia y distinción, acompañándose de detalles como las hojas de laurel bordadas con hilos de oro, símbolo de valentía, tal y como las llevaban en la antigua Grecia aquellos a quienes se consideraba victoriosos.

En la figura 3 se observa a Simón Bolívar con un atuendo compuesto por una camisa de algodón blanca de cuello alto y recto, almidonado y rígido para crear una pose de elegancia y estirpe, acompañado por una chaqueta diseñada con una pechera frontal de botonadura dorada lateral simulando un escudo de color rojo escarlata como símbolo de fuerza y valentía, o, como lo describe Geringer (2001, p. 2), rojo positivo, enérgico e impulsivo. Adicionalmente, en diversas obras realizadas por José María Espinosa y Pedro José Figueroa el pantalón lo retratan de color rojo o blanco; para tal caso, el blanco es símbolo de neutralidad y equilibrio. Su estructura está inspirada en los trajes masculinos de la época del barroco y rococó, conocidos como culotte: dicha prenda era de largo hasta la rodilla, según diversos historiadores; no obstante, cada prenda se iba adaptando al contexto y este pantalón pudo ir un poco más abajo, quizás hasta la pantorrilla o a los tobillos. Finalmente, acompañan todo el atuendo unas botas de cuero caña alta.

Teniendo en cuenta lo anterior se postula una paleta cromática elaborada a partir de colores primarios: azul como base o complemento y rojo como dominante, mientras que el amarillo se interpreta sobre el tono dorado, determinado como el color de acento o énfasis, por lo que tales matices demuestran un balance de luminosidad.

Las dos obras anteriores demuestran una jerarquía de color en la que el rojo toma protagonismo, tal y como se puede observar en la figura 4: visualmente, un primer acercamiento permite crear un mapa secuencial donde el color rojo cubre un $50 \%$ de toda la paleta, el dorado se percibe en un $20 \%$ y el azul se evidencia en un $30 \%$, como un color sofisticado y apropiado para dar una proporción sensorial equilibrada. 


\section{Francisco de Paula Santander y Juan José Reyes Patria}

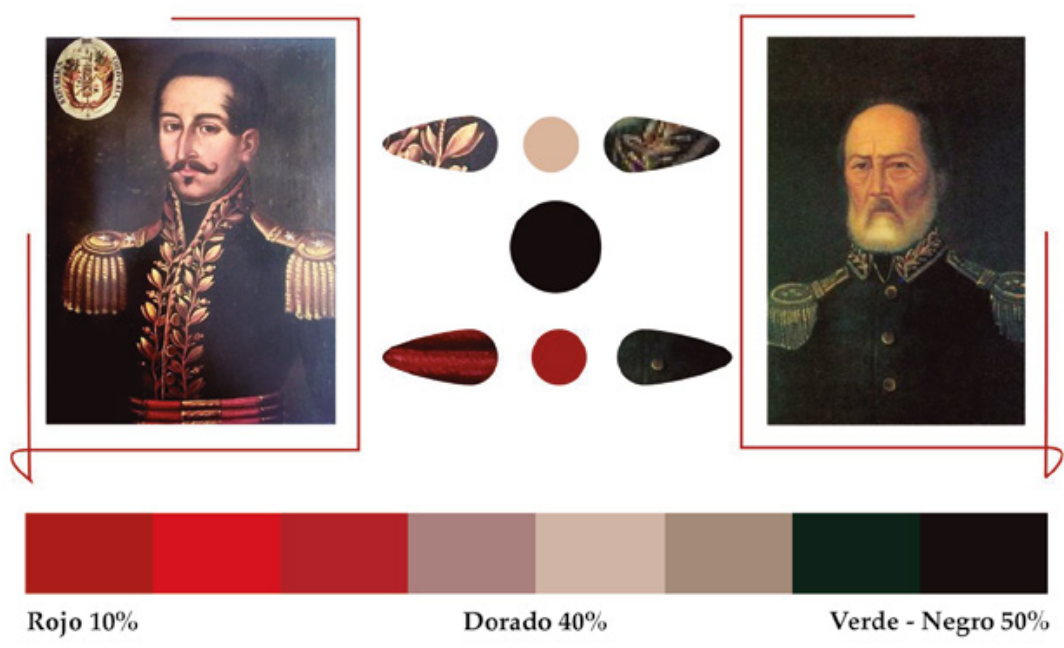

Figura 5. Francisco de Paula Santander (anónimo, s.f.). Fuente: Casa del Florero. Ministerio de Cultura.

Figura 6. Juan José Reyes Patria (anónimo s.f.). Fuente: Museo Nacional.

Las figuras 5 y 6 muestran un equilibrio de color básico, donde el azul y el verde correspondientes a cada persona constituyen los tonos dominantes, mientras que su complemento está oculto; sin embargo, según narraciones históricas, la estructura del vestuario militar solía ser acompañada por camisas de algodón blancas, con cuello tipo nerú o camisero alto, convirtiéndose el blanco en un tono sobrio y neutral para la rigidez de dicho atuendo. Adicionalmente, es importante recalcar el valor del trabajo manual en estos trajes, con técnicas artesanales y de gran costo como el bordado con hilos de oro, siendo así un detalle relevante y a su vez un color dorado de acento para la composición del atuendo. Dichos oficios manuales hicieron la diferencia, y permitieron también evidenciar el rango social de clase alta al cual pertenecían estos personajes; la labor manual era elaborada con tal compromiso que abarcaba un tiempo moderado de realización, por lo mismo tenía un valor significativo que solo la burguesía podía costear. 
El color verde se define a partir de las sensaciones que percibe el ser humano y de su capacidad para relacionarlo con objetos de la naturaleza, en términos de López (2014, p. 100), "es [el color] de la vida misma, del renacimiento de la primavera, del permanente poder de la naturaleza. Simboliza la esperanza, la fe y la regeneración. Representa armonía, crecimiento, exuberancia, fertilidad y frescura". De lo anterior, sería válido teorizar que la expresión por medio de atuendos y colores no solo era símbolo de poder, sino de liderazgo y esperanza para el pueblo; es el caso de Juan José Reyes, quien es el personaje que exhibe tal tonalidad, la cual expresa no solo un estatus de autoridad sino también de respaldo en la gesta libertadora.

En cuanto al color azul, se encuentra en diversas ilustraciones de Francisco de Paula Santander, gran político y dirigente militar en la época independentista, donde se muestra como un hombre firme y decisivo. De acuerdo con López (2014, p. 100), el color azul "representa la lealtad, la confianza, la sabiduría, la inteligencia, la fe, la verdad [...]. Se le considera un color beneficioso tanto para el cuerpo como para la mente ya que ejerce un efecto relajante y rebaja la presión". En el caso de Santander, hombre reconocido por su labor y grandes aportes a la sociedad de la Nueva Granada, según la representación en diversas imágenes su liderazgo se expresa por medio del tono azul, si bien la cita descrita es totalmente válida, ya que no solo Francisco de Paula Santander y Simón Bolívar, sino varios militares memorables, implementaron la paleta de color azul para reflejar su sabiduría, conocimiento y lealtad con las comunidades a las cuales brindaron aportes importantes.

Adicionalmente, en la pintura presentada de Santander se observa el color negro, siendo un color asociado con la elegancia y el carácter, que permite reflejar un carácter empoderado por parte del personaje, un ser de estirpe y templanza. 


\section{c. Pedro Pascasio Martínez}

\section{Pedro Pascasio Martínez}

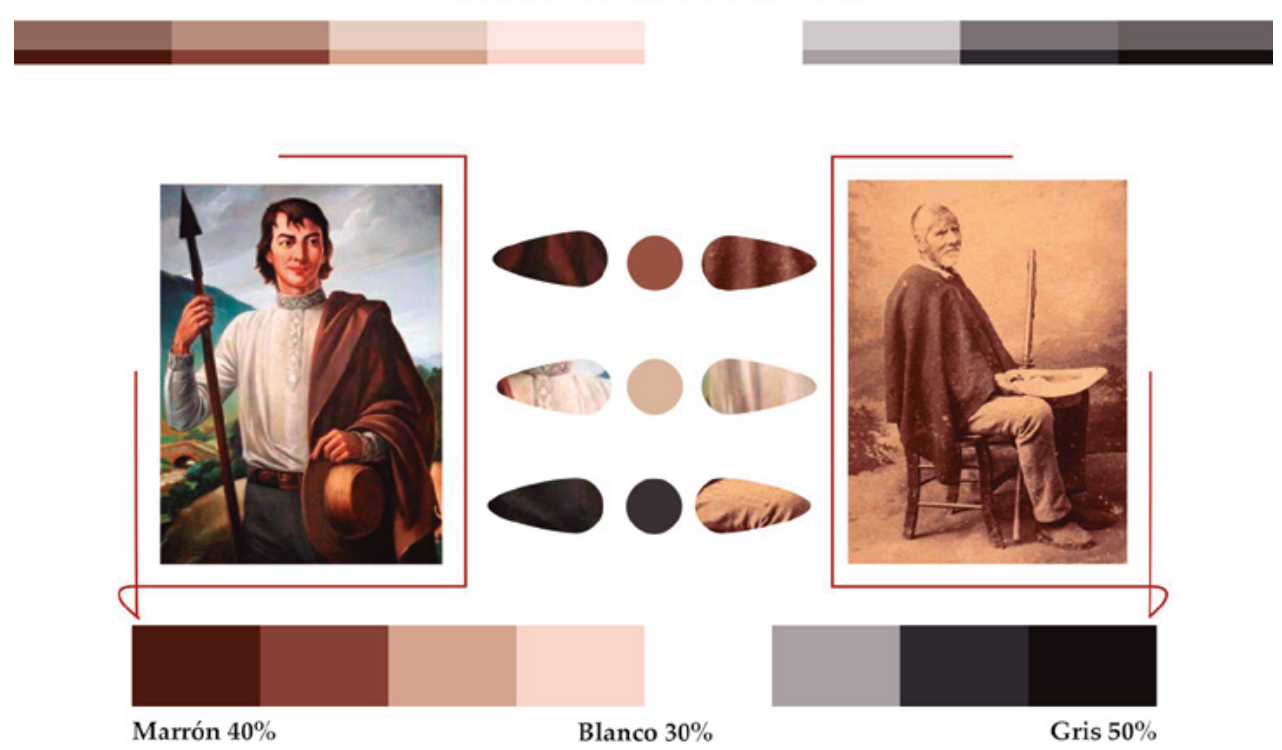

Figura 7. Ilustración Pedro Pascasio Martínez (anónimo, s.f.). Fuente: Archivo Distrital de Bogotá.

Figura 8. Pedro Pascasio Martínez. Fuente: Galería de Notabilidades Colombianas recopilada por José Joaquín Herrera Pérez (1883).

Pedro Pascasio Martínez, oriundo del municipio de Belén (Boyacá), soldado voluntario de la campaña libertadora para apoyar al ejército del Libertador Simón Bolívar, es referente clave de las clases populares de la época. La estructura de su vestuario, para Ortega y Gasset, citado en Martínez (1995, p. 21), es "el harapo: planteado como único traje, no solo universal sino eterno [...] se diferencian muy poco al mendigo contemporáneo, cuyos harapos imitan a los rebeldes de las sociedades más ricas"; de igual manera, para Rivadeneira (2010, p. 292), "Harapiento: significa la perdida de juicio, que se hace evidente en este caso como el desarreglo del vestido". Cada uno llega a la conclusión de que es un traje para la clase baja inspirado en los 
descamisados revolucionarios franceses, conformado por un pantalón bota recta sin terminaciones que recibía el nombre de pantalón campesino (con referencia al tradicional sans culotte), una camisa blanca de cuello ancho y una ruana tejida. Estas prendas estaban elaboradas en fibras naturales, como el algodón y el lino, y lana de oveja para el caso de la ruana.

Ahora bien, el análisis de color para este personaje es básico, podría decirse monocromático o a dos tonos, resaltando el color marrón y su balance análogo en la paleta de color presentada, donde se identifica una variación dominante de este tono representativo con un $40 \%$ de presencia, seguido de colores sobrios como el blanco y el negro, los cuales reciben valores del 30\% cada uno. El color marrón era dominante puesto que las prendas de abrigo, como la ruana y el sombrero, tenían dicho color, lo que capta la atención con relación a la intensidad que se maneja en tonos neutros como el blanco (o color crudo, por la fibra en la que se elabora); luego se observa un pantalón de color gris o negro, los tonos complementarios o subordinados. Los colores de acento en la clase media se evidencian con mayor detalle en los atuendos de las mujeres.

Pedro Pascasio ha sido emblema para una sociedad humilde y trabajadora, demostrando su valor y coraje en su actuación como soldado durante la campaña libertadora. Provenía de un departamento de clima principalmente frío, y como prenda principal utilizaba la ruana, una capa de cuatro puntas elaborada en lana virgen y tinturada de forma natural, muy característica de Colombia; para Rivadeneira (2010, p. 281), la ruana "se constituyó en un símbolo de la nacionalidad. En la independencia se advierte el uso de la ruana en dos grupos sociales. El primero, conformado por indígenas [...]. El segundo se trataba de una 'clase media' conformada por campesinos".

Finalmente, y con relación al personaje expuesto se encuentra una descripción del traje masculino de clase media, la cual se expondrá a continuación.

\footnotetext{
Se caracterizaban estos individuos por ser poseedores de un caballo brioso que lo mostraban en cierta medida más poderoso, usaban, además: zamarros de piel de felino, camisa de manga larga, poncho o ruana (preferiblemente de rayas multicolores), una pañoleta roja amarrada a la cabeza (que los hacían llamar 'pajarones') y un sombrero de ala ancha y de copa alta, hecho de fibra o de fieltro. (Rivadeneira, 2010, p.281)
} 


\section{Vestuario femenino}

La representación de color en los atuendos femeninos no era nada extravagante, en la medida en que, como bien se referenció previamente, la influencia romántica y neoclásica determinó una paleta de tonalidades análogas, sobre todo primarias.

En los diversos atuendos de las mujeres de la Nueva Granada se halló una argumentación referente a la influencia europea en sus vestidos y a la forma como ellas la adaptaron.

En algunas pinturas se observan características del vestido romántico en el traje de las señoras colombianas, pero, cosa curiosa, aunque los vestidos y el calzado estuvieran a la moda, algo fallaba en el conjunto y como se aprecia en las ilustraciones de la época, la vestimenta de las colombianas no concuerda con la que difundían los figurines europeos. (Martínez, 1995, p. 138)

En el análisis que se presenta a continuación, la estructura de cada atuendo es descrita siguiendo a esta autora, teniendo en cuenta las características generales, los rasgos determinados desde la perspectiva de la moda tradicional y las formas creadas a partir de cada personaje 
Manuelita Sáenz

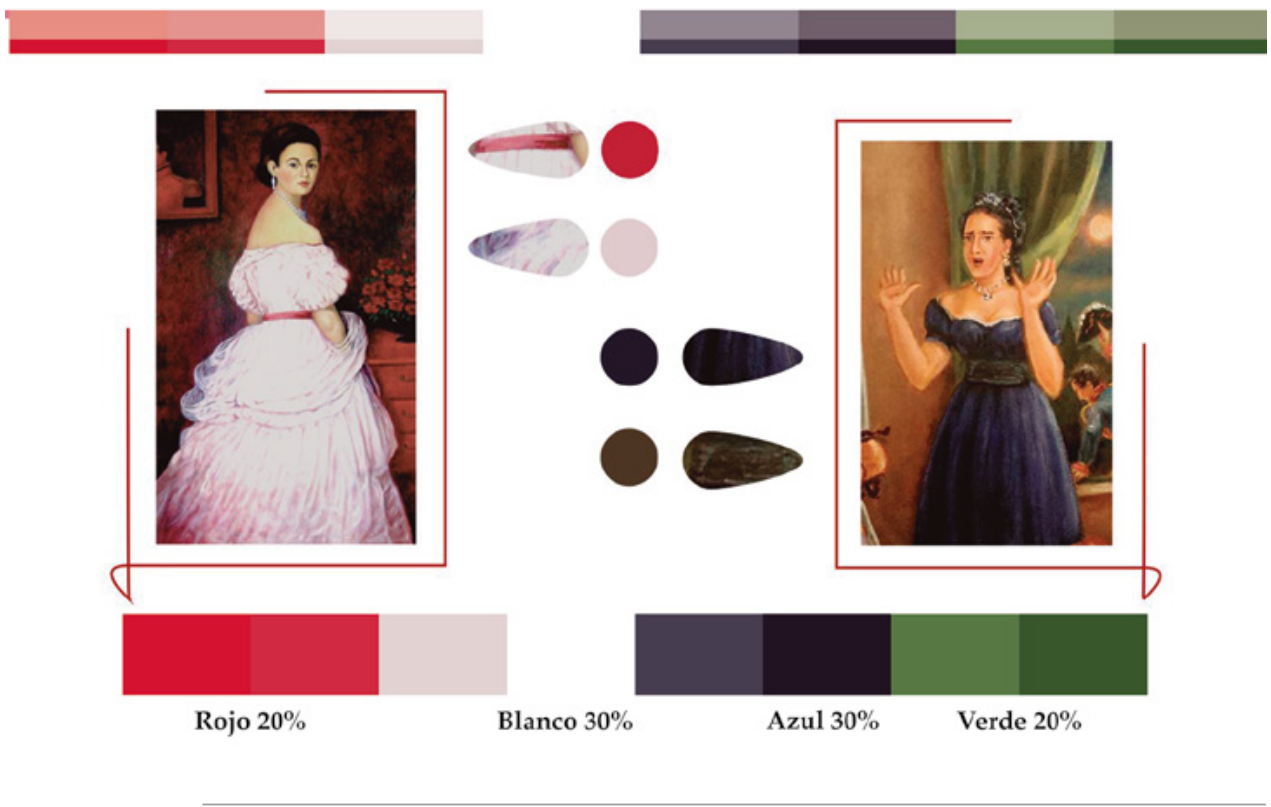

Figura 9. Manuelita Saenz (anónimo, s.f.). Recuperado de: https://globovision.com/article/m1

Figura 10. Manuelita Saenz (Delfín Ibáñez Carrero, 2010). Fuente: Mujeres y la libertad (Nelly Sol Gómez de Ocampo, 2011).

Manuelita Sáenz, reconocida como la libertadora del Libertador, resulta un icono relevante como comparativo de las mujeres que hicieron parte de la gesta libertadora. La construcción de su vestuario se analiza en la imagen a partir de una codificación propia de formas de vuelo ampuloso y de corte rotonda implementadas durante el romanticismo europeo; luego se observa el escote prominente y ajustado, con un fajón o pieza de estómago ajustando el torso de su cuerpo, por lo cual no podría definirse como de una total influencia neoclásica, si bien se tiene presente el realce de su busto al estilo de corte imperio.

Las imágenes ilustradas son muy pocas, pero la variación de color se da de manera predominante en una paleta de tonos fríos, dándole prioridad al azul y al verde, complementados por detalles como la joyería, guantes, carteras, entre otros. 
Las mujeres de clase alta solían utilizar el color verde en sus vestidos; Eva Heller (2008, p. 115) define este tono como "el color de la burguesía", de forma que entre más puro más elevaba el rango social, y propone que estas tonalidades oscuras de azul y verde brindaban un significado distintivo, de sofisticación y elegancia, que permitía acentuar las figuras estilizadas de la época.

El atuendo de Manuelita Sáenz es un referente básico para las esposas de hombres importantes que reciben una influencia francesa, inglesa y española; la implementación de encajes tejidos en croché con hilos de seda permite resaltar su feminidad, al igual que diferencia su posición social, así como el trabajo artesanal refleja su distinción ante otras clases.

\section{b. Juana Escobar y Simona Amaya}

\section{Juana Escobar y Simona Amaya}

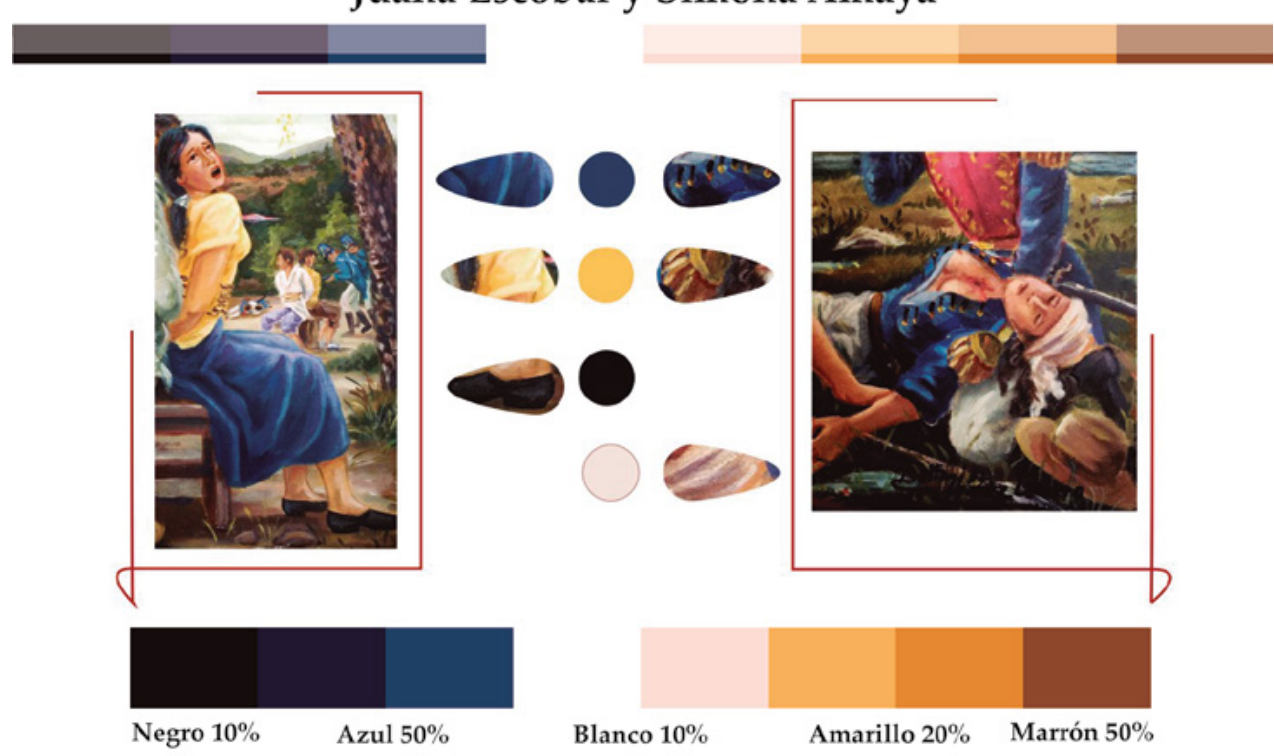

Figura 11. Representaciones de Juana Escobar y Simona Amaya (Delfín Ibáñez Carrero, 2010). Fuente: Mujeres y la libertad (Nelly Sol Gómez de Ocampo, 2011). 
La paleta de color observada en la figura 11 se define por colores primarios como el azul y el amarillo, en el caso de Juana Escobar, con un balance del $50 \%$ para ambos tonos; su único tono de énfasis estaría en los zapatos de cuero, representados en color negro.

Las prendas en este análisis son básicas, en el caso de Juana usa una falda campesina semi-rotonda elaborada en paño de lana y una blusa tejida en fibra natural (como el lino o el algodón) que implica su uso en clima frio, dado el abrigo que ofrecía este atuendo.

Según una referencia de 1887 por parte de José Caicedo Rojas (citado en Martínez, 1995, pp. 139-140), "el vestido de las señoras consistía en una mantilla azul o negra, de paño [que] caía sobre los hombros, dejando libres los globos de las mangas y cubriendo la espalda. Además de una falda de paño o seda, azul o negra, recogida en la cintura". El mismo autor describe como prendas complementarias a las camisas de manga larga blanca elaboradas en algodón y a las enaguas como pantaletas o faldas interiores.

c. Matilde Anaray y Casilda Zafra

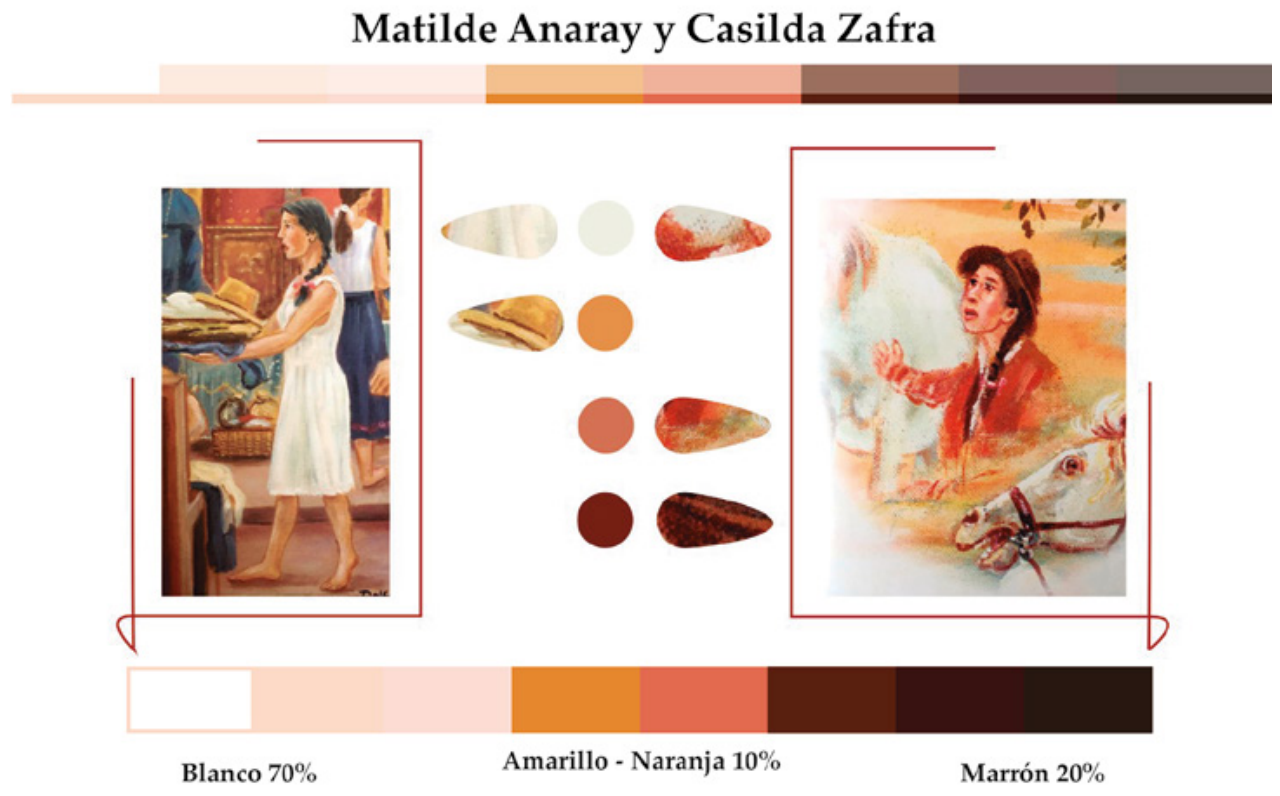

Figura 12. Representaciones de Matilde Anaray y Casilda Zafra (Delfín Ibáñez Carrero, 2010). Fuente: Mujeres y la libertad (Nelly Sol Gómez de Ocampo, 2011). 
Casilda Zafra y Matilde Anaray son heroínas de la gesta libertadora y su imaginario las proyecta como mujeres solidarias y guerreras. Es casi imposible juzgar su rango social, debido a que las narraciones de su apariencia son prácticamente nulas; no obstante, en las ilustraciones del artista Delfín Ibáñez se pueden establecer prendas básicas como el vestido de algodón de color blanco, con un mínimo ajuste hacia la cintura, inspirado en un corte español tradicional, acompañado de una mantilla o ruana sencilla de color café o de tonos cálidos que podrían variar entre el rojo, el naranja y el amarillo en diferentes valores, siendo el énfasis o acento de sus atuendos frente a un color básico y equilibrado como el blanco.

Según diversos autores, entre ellos Aída Martínez, se destaca la pulcritud en cada prenda; importante rescatar también la humildad de la clase baja reflejada en ambos personajes, cuyos miembros se describían como individuos descalzos, o algunos usaban alpargatas de fique, si bien para el momento estos accesorios también acarreaban ciertos costos que los hacían innecesarios.

Al implementar colores primarios, las paletas de color del vestuario femenino evidencian desde cierta perspectiva el sentido de pertenencia por los colores patrios y el hecho de hacer parte de la campaña libertadora por medio de prendas que expresaran su compromiso. 


\section{CONCLUSIONES}

La semiótica visual es un enfoque metodológico que permite analizar de forma holística la influencia del color en el traje y sus demás componentes, descomponiendo de forma sistémica cada una de las partes estructurales, formales y estéticas de un atuendo, para comprender su influencia social en un periodo histórico específico, lo cual posibilita elaborar un discurso sobre la moda y su influencia como patrimonio cultural mueble.

En lo que respecta al diseño de moda y la interpretación del color, se puede afirmar que su análisis no se puede realizar de forma aislada, puesto que en este caso el objeto semiótico es una prenda de vestir en la que interviene una corporalidad o sujeto que expone y complementa el significado de la misma.

De igual forma la prenda de vestir o indumentaria y los accesorios que la complementan forman un conjunto de códigos que son susceptibles a cambios, por el contexto y la cultura en la que se ve inmerso el sujeto que la viste o expone a los demás.

El análisis del color permite entender el comportamiento de la época, y su clara y marcada diferencia en cuanto a género, clase social y oficio. Se observan colores fuertes y tonalidades de colores primarios en individuos de género masculino (militares), y colores pasteles y terrosos para representantes del género femenino (heroínas de la patria). Así mismo, se tiene en cuenta el grado e impacto porcentual que tiene un determinado color para el ojo humano y cómo se distribuye o posiciona en una parte específica de la prenda.

La comunicación de la moda es una variante cuyo estudio abarca hallazgos desde la prehistoria, vestigios que permiten construir narraciones del ser humano y su evolución a través del tiempo; no obstante, a nivel nacional no existen aún bases bibliográficas sólidas, sino solo un pequeño conjunto de autores especializados de referencia. La escasa fundamentación teórica de la disciplina a nivel local dificulta encontrar una definición válida para esta investigación. Sin embargo, hemos comprobado cómo la dimensión comunicativa de la moda ha despertado un interés pluridisciplinar, aunque sin obtener resultados y conclusiones realmente satisfactorios. 


\section{REFERENCIAS BIBLIOGRÁFICAS}

Costa, J. (2003). Diseñar para los ojos. Barcelona, España: Design.

Eco, U. (1968). La estructura ausente. Introducción a la semiótica. Barcelona: Lumen.

Davis, F. (1992) Fashion, Culture, and Identity, Chicago: The University of Chicago Press. Fischer, R., y Mikosch, G. (1984). Grundlagen einer Theorie der Produktsprache. Anzeichenfunktionen, editado por Hochschule für Gestaltung, Offenbach am Main.

Gros, J. (1984). Reporting Progress Through Product Language. Innovation, The Journal of the Industrial Designers Society of America, Spring 1984, 10-11.

Heller, E. (2008). Psicología del color. Barcelona: Editorial Gustavo Gilli.

Karam, T. (2011). Introducción a la semiótica de la imagen. Barcelona: Portal de la comunicación incomUAB: el portal de los estudios de comunicación. Cerdanyola del vallès.

Löbach , B. (1981). Diseño Industrial. Bases para la configuración de los productos industriales. Barcelona: Editorial Gustavo Gili.

López, A. M. (2014). Curso diseño gráfico. Fundamentos y técnicas. Madrid: Ediciones Anaya Multimedia.

Lurie, A. (1994). El lenguaje de la moda: una interpretación de las formas de vestir. Barcelona: Paidós Iberia.

Martínez, A. (1995). La prisión del vestido. Santa Fe de Bogotá: Planeta Colombiana Editorial S.A.

Medina Caro, F. (2008). La moda, el sentido del vestir y la posmodernidad. Iconofacto. Revista de la Escuela de Arquitectura y Diseño, 4(5),11-26.

Polidoro, P. (2016). ¿Qué es la semiótica visual? Bilbao: Servicio Editorial de la Universidad del País Vasco, España.

Radulescu, M. (2016). 24 horas de fundamentos discursivos para la semiótica del diseño. Perú: Facultad de Arte y Diseño, PUCP.

Radulescu, M. (2017). Segundo Simposio de Semiótica de la Moda, 1 parte. Perú: Facultad de Arte y Diseño, PUCP. 
RAE (s.f). Definición de la palabra "estructura". Obtenido de: http://dle.rae.es/srv/search?m=30\&w=estructura

Retana, C. (2014). Las artimañas de la moda: hacia un análisis del disciplinamiento del vestido (Tesis de posgrado). Universidad Nacional de la Plata. Facultad de Humanidades y Ciencias de la Educación. Recuperado de: http://www.memoria.fahce.unlp.edu.ar/tesis/te.982/te.982.pdf

Rivadeneira, R. (2010). Moda y trajes en la época de la Independencia. En P. Rodríguez (dir.) Vida cotidiana y cultura material en la Independencia. Bogotá: Alta Consejería para el Bicentenario, Fundación Bicentenario, MNR ediciones.

Rodriguez, P. (Ed.) (2010). Historia que no cesa: La independencia de Colombia 1780-1830. Bogotá D.C.: Editora de la Universidad El Rosario.

Saussure, F. (2014). Curso de lingüística general (Antología anotada). Madrid: Akal Ediciones.

Shin, Y. (2015). El efecto sobre las emociones y la actividad cerebral por la luz directa / indirecta en el entorno residencial. Neuroscience letters, 584, 28-32.

Verón, E. (1993). La semiotica social. Barcelona: Gedisa.

Volli, U. (2001). ¿Semiótica de la moda, semiótica del vestuario? deSignis, (1), 57-70.

Zimmermann, Y. (1988). Del diseño. Barcelona: Gustavo Gili.

Zumalde, I. (2016). Oda al sentido común. Eu-topias, 12, 161-163. 